\title{
Increased bronchial responsiveness to exercise as a risk factor for symptomatic asthma: findings from a longitudinal population study of children and adolescents
}

\author{
C.S. Ulrik*, V. Backer**
}

Increased bronchial responsiveness to exercise as a risk factor for symptomatic asthma: findings from a longitudinal population study of children and adolescents. C.S. Ulrik, V. Backer. (CERS Journals Ltd 1996.

ABSTRACT: The prevalence of asthma seems to be on the increase and risk factors are not well-established. To investigate the relationship between asymptomatic increased bronchial responsiveness to exercise (BRE) and subsequent development of asthma, we studied a population sample of children and adolescents, aged 7-17 yrs at enrolment, examined twice 6 yrs apart (54 and $68 \%$, respectively, of the original sample participated in the two examinations). Complete information was available for 383 subjects (191 males and 192 females).

Case history and questionnaire data were obtained and were used to assess the presence or absence of symptomatic asthma. Exercise testing, performed at enrolment only, consisted of steady running on a $10 \%$ sloping treadmill for 6 min in a climate chamber. BRE was recorded as percentage fall in forced expiratory volume in one second $(F E V 1)$ from pre-exercise FEV1, within 15 min after exercise.

Twenty subjects $(5 \%)$ had asthma at enrolment, whereas 58 subjects $(15 \%)$ had current asthma (i.e. symptoms within the preceding 12 months) at the time of follow-up, of whom 40 were asymptomatic at enrolment (new asthma). In general, increased BRE at enrolment was significantly associated with symptomatic asthma at follow-up. Analysing the data for subjects who were asymptomatic at enrolment $(n=363)$, showed that new asthma at follow-up was not predicted by increased BRE at enrolment, whether BRE was evaluated as a continuous $\left(R^{2}=0.06, p=0.13\right)$ or dichotomous (cut-off: $B R E=10 \%$ decline in FEV1; odds ratio (OR) $0.8(0.4-1.2)$; $\mathrm{p}=\mathbf{0 . 1 1}$ ) variable. However, the data do not exclude the possibility that asymptomatic subjects with BRE $>\mathbf{1 5 \%}$ have an increased risk for subsequent development of asthma.

The findings of the present study suggest that increased bronchial responsiveness to exercise in asymptomatic children and adolescents is not a strong predictor for subsequent development of symptomatic asthma. Further studies, preferably of larger samples, are needed to confirm these findings.

Eur Respir J., 1996, 9, 1696-1700.
*Dept. of Clinical Physiology \& Nuclear Medicine KF, Rigshospitalet, Copenhagen, Denmark.

**Dept. of Pulmonary Medicine P, Bispebjerg Hospital, Copenhagen, Denmark.
Correspondence: C.S. Ulrik
Lollandsvej 31, 1.tv.
DK-2000 Frederiksberg
Denmark

\section{Keywords: Asthma children and adolescents exercise challenge test population sample risk factors}

Received: October 31995 Accepted after revision April 301996

This study was supported by the National Union for the Fight against Lung Diseases.
Bronchial hyperresponsiveness to histamine, methacholine and exercise is a common finding in patients with current symptomatic asthma, but may also be observed in subjects without respiratory symptoms $[1,2]$. In patients with current asthma, a close correlation has been demonstrated between bronchial responsiveness to histamine and methacholine [3]. However, the findings concerning the relationship between responsiveness to pharmacological agents and exercise in asthmatics have yielded conflicting results $[4,5]$. The latter supports the assumption that responsiveness to these two types of stimuli probably reflects different components of airways dysfunction [6].

The prevalence of asthma appears to be on the increase in many industrialized countries, not least in children and adolescents [7-9]. However, risk factors for symptomatic asthma are not well-established. Hopp and co-workers [10] have previously reported that asymptomatic airway hyperresponsiveness to inhaled histamine is a strong predictor for subsequent development of asthma. But, to our knowledge at least, the relationship between asymptomatic increased responsiveness to exercise and subsequent development of asthma has not been extensively studied.

To further evaluate potential risk factors for asthma, we examined a population sample of children and adolescents on two occasions, 6 yrs apart, in order to study the relationship between exercise-responsiveness and subsequent development of symptomatic asthma.

\section{Material and methods}

\section{Subjects}

A sample of 983 children and adolescents living in the area surrounding Rigshospitalet, in Copenhagen, was drawn at random from the civil registration list in 1986. 
All subjects were born in the first week of each month, were 7-17 years of age and Caucasian. In 1986 "baseline study" and 1992 "follow-up study", all subjects were invited by letter to participate in a study concerning asthma, allergy and bronchial hyperresponsiveness.

Of the 983 subjects, 527 (54\%) participated in the baseline study and $665(68 \%)$ in the follow-up study; 408 subjects (199 males and 209 females) participated in both examinations. The comparison of these 408 subjects both to the drop-outs and the newcomers has been published previously [11]. Briefly, no significant differences were found between the subjects (stayers) and the drop-outs with respect to anthropometric data or pulmonary function. At enrolment, the number of subjects among dropouts $(n=119 ; 23 \%$ of the subjects who participated in the baseline study) with symptomatic asthma $(n=5)$, rhinitis and/or eczema $(n=14)$, a positive skin-prick test $(n=32)$, and a positive histamine challenge test $(n=11)$ did not differ significantly from the numbers found among the 408 subjects who participated in both examinations. Likewise, these numbers did not differ between the newcomers and the 408 subjects (stayers). Of the 199 subjects $(20 \%$ of the original sample) who participated in neither of the examinations, case history was obtained by telephone or letter from 124 subjects, which means that a more or less detailed medical history was available for 908 subjects ( $92 \%$ of the original sample). The proportion of subjects reporting symptoms suggesting a diagnosis of asthma did not differ substantially between the 124 subjects described above and the 408 subjects who participated in both examinations. We therefore assume that the 408 subjects are representative of the whole sample.

From the total sample of 408 subjects $(42 \%$ of the original sample) who attended both examinations, $25 \mathrm{sub}$ jects with incomplete data required for this analysis were excluded. The final study sample, therefore, comprised 383 subjects, 191 males and 192 females.

\section{Case history}

The participants and, if present, their parents were interviewed by one person concerning birthweight, diseases (respiratory and nonrespiratory), active and passive smoking, use of medication, known or suspected allergic disease/allergy, pets in the household, and use of eiderdown and carpets in the bedroom.

Furthermore, all participants filled in a questionnaire about asthmatic (see below) and allergic symptoms, i.e. rhinits (sneezing, running or blocked nose not associated with a cold) and eczema (an itchy dry rash on face, arms or legs), as related to themselves, their siblings and their parents.

The questionnaire concerning respiratory symptoms and the definition of asthma were adapted from the American Thoracic Society (ATS), Division of Lung Disease of the National Heart, Lung, and Blood Institute (NHLBI) [12, 13], and Hopp and co-workers [10, 14]. Asthma was defined by questionnaire criteria based on the responses to the following questions: 1) Have you ever had asthma?; 2) Does your breathing ever sound wheezy or whistling?; 3) Do you have attacks of shortness of breath with wheezing?; 4) Do you experience wheezing, chest tightness, cough, breathlessness with any of the following: at rest, with exertion, with emotional stress, with exposure to cold air, with chest infections or head cold?; 5) Do you experience wheezing after exposure to: dust, fumes, moulds, pollen, food, pets or drugs?; 6) Have you ever been hospitalized or observed and treated by a doctor for asthma?; 7) Have you ever received medication for your asthma?; 8) What was the medication that was used?; 9) Did it help?; 10) How many episodes of wheezing have you had during the last year? and 11) Have you ever had attacks of wheezing, shortness of breath or dry cough at night? Asthma was defined on the basis of positive responses to at least Questions 2 and 3, and 4 and/or 5. Current asthma was defined as symptoms within the preceding 12 months.

\section{Pulmonary function tests}

The forced expiratory volume in one second (FEV1) and forced vital capacity (FVC) were measured with a 7 L dry wedge spirometer (Vitalograph $®$ ), which was calibrated weekly. Each measurement consisted of at least three maximal expiratory manoeuvres from total lung capacity (TLC) to residual volume (RV) with a variation of less than $5 \%$ in FEV1. The highest FEV1 and $\mathrm{FVC}$ were used in the analyses.

The subjects were asked to abstain from smoking for at least $2 \mathrm{~h}$ before the examination. If they were taking medication for asthma/allergy, they were asked not to take theophylline or an antihistamine for at least $24 \mathrm{~h}$, astemizole for 6 weeks, or an oral $\beta_{2}$-agonist for $18 \mathrm{~h}$, and not to use an inhaled bronchodilator for $6 \mathrm{~h}$ before the tests. They continued with any inhaled or oral corticosteroids they were using. In the event of recent respiratory tract infection, the tests were postponed for 6 weeks.

Data on pulmonary function are expressed as a percentage of predicted values (\% pred), using prediction equations based on age, sex and height $[15,16]$. Unless otherwise stated, values obtained after administration of bronchodilator are used in the analyses.

\section{Exercise challenge test}

The exercise challenge test was only performed at enrolment (baseline study) in 1986. Bronchial responsiveness to exercise was tested by steady running on a $10 \%$ sloping treadmill for $6 \mathrm{~min}$ in a climate chamber (temperature $21^{\circ} \mathrm{C}$ and relative humidity $40-50 \%$ ) $[17,18]$. The speed was adjusted to maintain the heart rate between 160 and 180 beats $\cdot \mathrm{min}^{-1}$. The response was measured by the FEV1, before (baseline value) and $0,1,3,5,10$ and 15 min after the test, each time the highest of three measurements was recorded. The lowest FEV1, within $15 \mathrm{~min}$ after exercise was recorded, and bronchial responsiveness to exercise (BRE) was calculated as the maximum decline in FEV1, from the prechallenge value, expressed as a percentage [9]. Subjects with a prechallenge FEV1 $<1.0 \mathrm{~L}$ were excluded from the exercise challenge test.

\section{Statistical methods}

Unless otherwise stated, variables are reported as arithmetric means and standard deviations. Correlation analysis 
was used to assess relationships between various variables. Logistic regression analyses were used to evaluate the potential relationship between level of exercise responsiveness and outcome at the second examination, i.e. the presence or absence of symptomatic asthma. A p-value less than 0.05 was considered significant.

\section{Results}

Baseline characteristics of the sample studied are presented in table 1. At enrolment, 57 subjects (29 males and 28 females) and 21 subjects ( 9 males and 12 females) had a fall in FEV1, of 10 and $15 \%$, respectively, following exercise. Of the 20 subjects with current asthma at enrolment 15 had a $10 \%$ or more postexercise decline in FEV1.

At the time of follow-up, 58 subjects (28 males and 30 females) had current asthma, of whom 40 had developed asthma at some time between the two examinations (new asthma). Two subjects with asthma at enrolment reported having had no symptoms of asthma within the 12 months preceding the second examination (former asthma).

Overall, a significant association was found between exercise responsiveness and current asthma at follow-up, whether BRE was evaluated as a continuous $(\mathrm{p}<0.001)$ or dichotomous (cut-off: $10 \%$ postexercise fall in FEV1; odds ratio (OR) $1.5(1.2-1.8) ; \mathrm{p}<0.001)$ variable. Using $15 \%$ decline in FEV1 following exercise as the cut-off between a positive and a negative test did not change these findings.

To further evaluate the association between exercise responsiveness and symptomatic asthma, subjects with current asthma $(n=20)$ at the time of enrolment were excluded from the analyses in order to ensure that the significant relationship between exercise and asthma was not driven by an association found primarily in asthmatics. Confining the analysis to subjects who were
Table 2. - Bronchial responsiveness to exercise at enrolment in a population sample of children and adolescents $(n=363)$, aged $7-17 \mathrm{yrs}$, divided according to gender and \% postexercise decline in $\mathrm{FEV}_{1}$; subjects with current asthma $(n=20)$ were excluded

\begin{tabular}{lrrrr}
\hline & \multicolumn{2}{c}{ Males } & \multicolumn{2}{c}{ Females } \\
& $\mathrm{n}$ & $\%$ & $\mathrm{n}$ & $\%$ \\
\hline Group 1 & 111 & 61 & 120 & 66 \\
Group 2 & 48 & 27 & 42 & 23 \\
Group 3 & 18 & 10 & 13 & 7 \\
Group 4 & 4 & 2 & 7 & 4
\end{tabular}

Group 1-4 defined as a postexercise decline in FEV1 of $<5$, $5-9.9,10-14.9$, and $>15 \%$, respectively. FEV1: forced expiratory volume in one second.

asymptomatic at the first examination $(n=363)$ revealed that new asthma at follow-up was not predicted by degree of exercise responsiveness at enrolment, whether BRE was evaluated as a continuous $\left(\mathrm{R}^{2}=0.06 ; \mathrm{p}=0.11\right)$ or dichotomous (cut-off: $\mathrm{BRE}=10 \%$ decline in $\mathrm{FEV} 1$; OR 0.8 $(0.4-1.2), \mathrm{p}=0.13)$ variable.

All nonasthmatic subjects at enrolment $(n=363)$ were further divided according to their postexercise fall in FEV1 as: Group $1<5 \%$ decline; Group $25-9.9 \%$ decline; Group 3 10-14.9\% decline; and Group $4>15 \%$ decline. The number of subjects in each group, divided according to gender, is given in table 2 .

Logistic regression analysis was used to assess the risk for development of symptomatic asthma in groups with different levels of responsiveness to exercise at enrolment. The results of the analysis are presented in table 3 . The asymptomatic subjects, who had a $15 \%$ or more postexercise decline in FEV1 at enrolment (Group 4), may have a higher risk for subsequent development of symptomatic asthma compared with the Group 1 subjects, who had almost unchanged postexercise FEV1. However, 32 of the subjects with new asthma had less than $10 \%$ postexercise decline in FEV1 (table 3).

Table 1. - Characteristics of the population sample of children and adolescents $(n=383)$, 7-17 yrs of age at enrolment, examined on two occasions 6 yrs apart

\begin{tabular}{lcccc}
\hline & \multicolumn{2}{c}{ Baseline study } & \multicolumn{2}{c}{ Follow-up study } \\
& $\begin{array}{l}\text { Females } \\
(\mathrm{n}=192)\end{array}$ & $\begin{array}{c}\text { Males } \\
(\mathrm{n}=191)\end{array}$ & $\begin{array}{c}\text { Females } \\
(\mathrm{n}=192)\end{array}$ & $\begin{array}{c}\text { Males } \\
(\mathrm{n}=191)\end{array}$ \\
\hline Age yrs & $13 \pm 3$ & $12 \pm 3$ & $18 \pm 3$ & $18 \pm 3$ \\
Height m & $1.52 \pm 0.14$ & $1.54 \pm 0.18$ & $1.67 \pm 0.06$ & $1.79 \pm 0.09$ \\
FEV1 & $2.4 \pm 0.7$ & $2.5 \pm 1.0$ & $3.5 \pm 0.5$ & $4.4 \pm 0.8$ \\
$\quad$ L \% pred & $95 \pm 12$ & $91 \pm 12$ & $98 \pm 11$ & $94 \pm 14$ \\
FEV1/FVC \% & $91 \pm 4$ & $87 \pm 6$ & $88 \pm 6$ & $86 \pm 7$ \\
Smoking habit n & 173 & 119 & 182 & 138 \\
$\quad$ Lifetime nonsmokers & 0 & 10 & 0 & 0 \\
Ex-smokers & 17 & 63 & 9 & 53 \\
$\quad$ Current smokers & $4.8 \pm 6.5$ & $4.7 \pm 6.2$ & & \\
BRE \% & 28 & 29 & & 28 \\
BRE 10\% n & 12 & 9 & 30 & \\
BRE 15\% n & 9 & 11 & & \\
Asthma* n & & & & \\
\hline
\end{tabular}

Values are presented as absolute number or as mean \pm SD. *: subjects with current asthma, defined as recurrent attacks of dyspnoea with wheezing triggered by exposure to allergens, respiratory infections and/or exercising, within the preceding 12 months. FEV1: forced expiratory volume in one second; \% pred: percentage of predicted value; FVC: forced vital capacity; BRE; bronchial responsiveness to exercise calculated as (baseline FEV1 - minimum postexercise FEV1) $\times 100$ baseline FEV1. 
Table 3. - Relationship of bronchial responsiveness to exercise at enrolment in asymptomatic children $(n=363)$ to symptomatic asthma 6 years later

\begin{tabular}{lccccc}
\hline & $\begin{array}{c}\text { Nonasthma } \\
\mathrm{n}\end{array}$ & $\begin{array}{c}\text { New asthma } \\
\mathrm{n}\end{array}$ & OR & $95 \%$ CI & p-value \\
\hline Group 1 & 207 & 24 & & & \\
Group 2 & 82 & 8 & 0.8 & $0.4-1.2$ & 0.69 \\
Group 3 & 26 & 5 & 1.8 & $0.6-3.0$ & 0.27 \\
Group 4 & 8 & 3 & 2.9 & $0.7-5.1$ & 0.14
\end{tabular}

\#: groups 2-4 compared to Group 1, who had less than 5\% decline in FEV1 following exercise. OR: odds ratio; 95\% CI: $95 \%$ confidence interval. For further definitions, see legend to table 2 .

Including prechallenge level of FEV1 in the statistical models did not substantially change these findings, but a weak but statistically significant correlation was found between prechallenge level of FEV1, and BRE, whether FEV1 was included in absolute values $(r=-0.11 ; p=0.036)$ or as a percentage of predicted $(r=-0.10 ; p=0.042)$. However, confining these analyses to subjects who were a symptomatic at enrolment, revealed no statistically significant correlation between level of FEV1 (in absolute values or expressed as \% pred.) and degree of BRE.

\section{Discussion}

The findings of the present study suggest that asymptomatic hyperresponsiveness to exercise is not a strong predictor for later development of symptomatic asthma. At enrolment, 42 subjects without respiratory symptoms had a postexercise decline in FEV1 of $10 \%$ or more; however, at the time of follow-up only eight of these subjects had developed asthma. Hence, although an overall association was found between exercise responsiveness and asthma, this was primarily driven by an association observed in subjects with known asthma, suggesting that asymptomatic hyperresponsiveness to exercise does not precede the development of asthma.

Hopp and co-workers [10] have previously demonstrated that, in a relatively small group of subjects, asymptomatic bronchial hyperresponsiveness to inhaled histamine in many cases precedes the development of symptomatic asthma. Exercise is a well-known trigger factor in many asthmatics, not least in children and adolescents, and hyperresponsiveness demonstrated by exercise challenge test may, therefore, be expected to be a better predictor for future development of asthma than hyperresponsiveness to direct stimuli such as histamine and methacholine. The present study, however, showed exercise hyperresponsiveness to be a poor predictor for development of symptomatic asthma within the following $6 \mathrm{yrs}$.

This observation contradicts previous findings reported by Jones [19]. Several factors may, at least partly, have caused this difference in findings. Firstly, there were differences in age between the groups studied, as the children in their study were aged 4-11 yrs when enrolled. Secondly, there were differences in methodology, free running and response measured by change in peak expiratory flow (PEF) rate compared to running on a treadmill in a climate chamber and measurements of FEV1. Thirdly, children selected from a primary care patient population might differ from the subjects enrolled in the present study. The FEV1 is a more reproducible index of pulmonary function than PEF [20]. It may, therefore, be reasonable to compare a postexercise fall in PEF of $15 \%$ with a $10 \%$ decline in FEV1. This comparison shows that the proportion of subjects with a positive test in the present study is almost twice that observed in the study by JONES [19]. Based on these considerations, in combination with the difficulties of maintaining a heart rate $>90 \%$ of the age-predicted maximum during free running, it may seem that the protocol used by JONES [19] may have identified asymptomatic children with generally more severe airway abnormalities than the protocol used in the present study. This is in keeping with the finding that the relative risk, although statistically insignificant, for development of asthma appeared to be higher in the children with the most pronounced exercise responsiveness. Therefore, although we fully acknowledge the potential importance of the larger sample of children studied by JONES [19] it seems, that the exercise challeng test may not be a useful screening test for risk for future development of asthma in large-scale population studies.

In interpreting the data presented here, it should be remembered that the conclusions are based upon only two sets of observations of the sample and, furthermore, on the result of a single exercise challenge test performed at enrolment. We are confident that the group of subjects included in the present analyses are representative of the entire sample $(n=983)$, as information on medical history was available for $92 \%$ of the subjects and no indications of nonresponder bias were found when the data on subjects who completed the exercise test and those who were not examined were compared. We are, however, aware of the possibility that studying a larger sample of subjects might have increased the statistical power of the study, leading to a statistically significant association between a very pronounced postexercise fall in FEV1 (that is $>15 \%$ ) and risk for subsequent development of asthma.

It is well-recognized that the proportion of asthmatics with exercise-induced respiratory symptoms is highest in children and declines substantially with increasing age. The relatively wide age range of the subjects included in the present study might, therefore, have influenced the findings, as the lack of an overall association between exercise responsiveness and development of asthma could be due to a lack of this association in the older subjects. The number of subjects in this study does not allow a detailed analysis, but analysing the data after dividing the subjects into two age groups or viewing a graphical presentation of the number of subjects with a positive exercise test at the different ages did not reveal obvious evidence that the age range of the subjects studied has had an impact on the findings.

It may be argued that subjects with a $15 \%$ or more decline in FEV1 following exercise are not truly asymptomatic. Although they did not report any respiratory symptoms at enrolment, they might have had mild symptoms not recognized as having bronchial asthma as the underlying cause, in keeping with previous findings by DoDGE et al. [21]. However, due to the length of followup and the fact that both the children and their parents were interviewed about respiratory symptoms, it seems unlikely that a substantial number of subjects have been misclassified as asymptomatic. 
In conclusion, this longitudinal population study of children and adolescents showed that, although hyperresponsiveness to exercise is closely associated with current asthma, increased bronchial responsiveness to exercise in asymptomatic subjects appears not to precede the development of symptomatic asthma.

\section{References}

1. Cockcroft DW, Murdock KY, Berscheid BA. Relationship between atopy and bronchial responsiveness to histamine in a random population. Ann Allergy 1984; 53: 26-29.

2. Sears MR, Jones DT, Holdaway MD. Prevalence of bronchial reactivity to inhaled methacholine in New Zealand children. Thorax 1986; 41: 283-289.

3. Juniper EF, Frith PA, Cockcroft DW, Dunnett C, Hargreave FE. Reproducibility and comparison of responses to inhaled histamine and methacholine. Thorax 1978; 33: 705-710.

4. Anderton RC, Cuff MT, Frith PA, et al. Bronchial responsiveness to inhaled histamine and exercise. J Allergy Clin Immunol 1979; 63: 315-320.

5. Clough JB, Hutchinson SA, Williams JD, Holgate ST. Airway response to exercise and methacholine in children with respiratory symptoms. Arch Dis Child 1991; 66: 579-583.

6. Godfrey S, Springer C, Noviski N, Maayan Ch, Avital A. Exercise but not methacholine differentiates asthma from chronic lung disease in children. Thorax 1991; 46: 488-492.

7. Peat JK, van den Berg RH, Green WF, Mellis CM, Leeder SR. Changing prevalence of asthma in Australian children. BMJ 1994; 308: 1591-1596.

8. Robertson CF, Heycock E, Bishop J, Nolan T, Olinsky A, Phelan PD. Prevalence of asthma in Melbourne schoolchildren: changes over 26 years. BMJ 1991; 302: 11161119.

9. Anderson HR, Butland BR, Strachan DP. Trends in prevalence and severity of childhood asthma. BMJ 1994; 308: $1600-1604$.
10. Hopp RJ, Townley RG, Biwen RE, Bewtra AK, Nair NM. The presence of airway reactivity before development of asthma. Am Rev Respir Dis 1990; 141: 2-8.

11. Ulrik CS. Comparison of stayers, drop-outs and newcomers in a longitudinal population study of asthma and bronchial hyperresponsiveness: introduction of bias? $J$ Asthma 1995; 32: 295-300.

12. Ferris BG Sr. American Thoracic Society Executive Committee. Epidemiology standardization project. Am Rev Respir Dis 1978; 118: 1-120.

13. United States Department of Health, Education and Welfare. Proceedings. First NHLBI Epidemiology Workshop. Washington, DC, United States Government Printing Office, 1971.

14. Hopp RJ, Bewtra AK, Nair NM, Townley RG. Specificity and sensitivity of methacholine inhalation challenge in normal and asthmatic children. J Allergy Clin Immunol 1984; 74: 154-158.

15. Zapletal A, Samanek M, Paul T. Lung function in children and adolescents: methods, reference values. In: Zapletal A, ed. Progress in Respiration Research. Vol. 22. Basel, Switzerland, Karger, 1987; pp. 114-116 \& 193.

16. Quanjer PH (ed). Standardized lung function testing. Bull Eur Physiopathol Respir 1983; 19 (Suppl. 5): 9.

17. Anderson SD, Silverman M, Konig P, Godfrey S. Exerciseinduced asthma. Br J Dis Chest 1975; 69: 1-39.

18. Backer V, Ulrik CS. Bronchial responsiveness to exercise in a random sample of 494 children and adolescents from Copenhagen. Clin Exp Allergy 1992; 22: 741-747.

19. Jones A. Asymptomatic bronchial hyperreactivity and the development of asthma and other respiratory tract illnesses in children. Thorax 1994; 49: 757-761.

20. Madsen F, Ulrik CS, Dirksen A, et al. Patient administered sequential spirometry in healthy volunteers and patients with alpha ${ }_{1}$-antitrypsin deficiency: qualifications of methods. Respir Med 1996; 97: 761-767.

21. Dodge R, Cline MG, Lebowitz MD, Burrows B. Findings before the diagnosis of asthma in young adults. $J$ Allergy Clin Immunol 1994; 94: 831-835. 